\title{
A Longitudinal SPECT Study of Different Patterns of Regional Cerebral Blood Flow in Alzheimer's Disease with or without Diabetes
}

\author{
Kentaro Hirao Haruo Hanyu Tomohiko Sato Hidekazu Kanetaka \\ Soichiro Shimizu Hirofumi Sakurai Toshihiko Iwamoto \\ Department of Geriatric Medicine, Tokyo Medical University, Tokyo, Japan
}

\section{Key Words}

Alzheimer's disease $\cdot$ Diabetes mellitus $\cdot$ Regional cerebral blood flow $\cdot$ SPECT

\begin{abstract}
Aims: To determine the effect of diabetes mellitus (DM) on regional cerebral blood flow (rCBF) patterns in patients with Alzheimer's disease (AD). Methods: We investigated the initial rCBF of 71 AD patients ( 36 without DM and 35 with DM) and the final rCBF of 23 AD patients ( 12 without DM and 11 with DM) after an average of 32 months. Single-photon emission computed tomography (SPECT) data were analyzed by statistical brain imaging. Results: The initial SPECT showed that $A D$ patients without $D M$ had lower $r C B F$ in the left and right inferior temporal gyri than $A D$ patients with DM. A follow-up SPECT demonstrated that $\mathrm{rCBF}$ decreased in more widespread regions, including the parietal, temporal, frontal, and limbic lobes, in AD patients without than with DM. Conclusion: This study suggests that functional brain abnormalities in AD differ depending on the DM status at baseline and during follow-up, reflecting neuropathologic differences.
\end{abstract}

Copyright $\odot 2011$ S. Karger AG, Basel

\section{Introduction}

Epidemiologic studies have shown that diabetes mellitus (DM) is associated with an increased risk of Alzheimer's disease (AD) [1]. Although multiple possible mechanisms explaining the association between DM and AD have been proposed, it is known that insulin 
resistance and peripheral hyperinsulinemia promote the neurodegeneration that occurs in $\mathrm{AD}$, for example due to $\beta$ amyloid (A $\beta$ ) deposits and the increase of tau hyperphosphorylation $[2,3]$. Indeed, some investigators have found that DM is associated with hippocampal and whole-brain atrophy $[4,5]$. However, it remains unclear whether there are any pathophysiologic differences between AD patients with and without DM. Moreover, it is controversial whether DM also plays a role in the progression of the disease itself [6-10].

In the present study, we first examined the differences in regional cerebral blood flow $(\mathrm{rCBF})$ deficits between $\mathrm{AD}$ patients with and without $\mathrm{DM}$ on initial single-photon emission computed tomography (SPECT) and then compared rCBF changes between initial and follow-up SPECT in each group. Since rCBF deficits reflect functional brain abnormalities associated with neuronal degeneration, repeated $\mathrm{rCBF}$ measurement is considered to be an objective and reliable indicator of disease progression. To the best of our knowledge, this is the first study on the effect of DM on rCBF patterns in AD patients.

\section{Materials and Methods}

\section{Subjects}

We retrospectively studied $71 \mathrm{AD}$ outpatients with or without type $2 \mathrm{DM}$ (27 men and 44 women, mean age \pm SD $78.7 \pm 5.2$ years) attending the Memory Clinic of our hospital. $\mathrm{AD}$ patients met the clinical criteria for probable $\mathrm{AD}$ established by the National Institute of Neurological and Communicative Disorders Association [11] and had mild-to-moderate AD defined according to a Clinical Dementia Rating score of 1 or 2 [12]. All patients underwent detailed general physical, neurologic, and psychiatric examinations and extensive laboratory tests including brain computed tomography (CT) or magnetic resonance imaging (MRI) to exclude other potential causes of dementia. After the initial evaluation, including SPECT, 66 of the $71 \mathrm{AD}$ patients were given donepezil at a dose of $3 \mathrm{mg}$ once daily for 2 weeks, followed by $5 \mathrm{mg}$ daily thereafter, which was tolerated without serious adverse effects. They were followed up for 24-48 months (mean follow-up time, $28.6 \pm 5.9$ months), but we could only obtain both the initial and final SPECT data in $23 \mathrm{AD}$ patients (12 without DM and 11 with $\mathrm{DM}$ ) because the intervals between cognitive assessment and SPECT in AD patients with and without DM who were lost to follow-up were unfortunately more than 3 months. The severity of cognitive impairment was assessed using the Mini-Mental State Examination (MMSE) [13]. Progression of dementia was evaluated based on a comparison of the MMSE scores on the initial evaluation and the final evaluation. Subjects were excluded if they had extensive white matter lesions (e.g., low-density lesions on CT or high-intensity lesions on T2-weighted MRI grade 3) using the scale of Fazekas et al. [14] and territorial or cortical infarctions. DM was defined as the use of an oral hypoglycemic drug or a casual (non-fasting) plasma glucose level of $\geq 200 \mathrm{mg} / \mathrm{dl}$ according to a report by the Expert Committee on the Diagnosis and Classification of Diabetes Mellitus [15]. The patients were divided into an AD without $\mathrm{DM}$ group $(\mathrm{n}=36)$ and an $\mathrm{AD}$ with $\mathrm{DM}$ group $(\mathrm{n}=35)$. The $\mathrm{AD}$ with $\mathrm{DM}$ group had been diagnosed with type $2 \mathrm{DM}$, and the duration of $\mathrm{DM}$ ranged from a few years to more than 30 years on the initial SPECT. Moreover, 10 of the $35 \mathrm{AD}$ patients with DM had already been receiving medication with oral hypoglycemic agents, including sulfonylureas, biguanides, and $\alpha$-glucosidase inhibitors at the time of initial SPECT, and 3 of the $11 \mathrm{AD}$ patients with DM with final SPECT were additionally given thiazolidinediones after the initial SPECT. The interval between cognitive assessment and SPECT in all subjects was $\leq 3$ months.

Twenty-eight control subjects ( 12 men and 16 women, age range 56-86 years, mean age \pm SD $77.1 \pm 6.4$ years) who had no memory impairment, cognitive disorder, or abnormali- 
ties on MRI were assigned to the normal control group. Written informed consent was obtained from all subjects or their closest relative before the study. The study design was approved by the ethics review board of our hospital.

\section{MRI Study}

Brain MRI scans (axial T1- and T2-weighted images) at the initial evaluation were obtained from $42 \mathrm{AD}$ patients (22 with $\mathrm{DM}$ and 20 without $\mathrm{DM}$ ) using a 1.5-tesla scanner (Magnetom; Siemens Medical Systems, Erlangen, Germany) with the following parameters: T1-weighted spin echo (TR $450 \mathrm{~ms}$; TE $12 \mathrm{~ms}$; FOV $250 \mathrm{~mm}$, matrix $256 \times 256$ ) and T2weighted fast spin echo (TR 3,540 ms; TE 106 ms; FOV $250 \mathrm{~mm}$, matrix $256 \times 256$ ). Qualitative MRI analysis was performed by blinded investigators who assessed periventricular and deep white matter hyperintensities (grades 0, 1, and 2 based on the scale of Fazekas et al. [14]), and lacunar infarctions (defined by low intensity on T1-weighted imaging and high intensity on T2-weighted imaging with a diameter $<15 \mathrm{~mm}$ ) in the deep gray and white matter (infarctions were rated as follows: no, single, and multiple).

\section{SPECT Study}

All subjects underwent examination using a triple-head rotating gamma camera (SPECT Picker 3000 XP; Eclipse Systems, Durham, Conn., USA) with a fan beam, permitting a spatial resolution of $6.8 \mathrm{~mm}$ full width at half maximum, approximately $15 \mathrm{~min}$ after an intravenous bolus injection of $222 \mathrm{MBq}$ of $\mathrm{N}$-isopropyl-p-[ $\left.{ }^{123} \mathrm{I}\right]$-iodoamphetamine. Prior to the injection, the subjects were allowed to rest in a quiet, dimly lit environment for $10 \mathrm{~min}$. SPECT acquisition was undertaken in 24 steps (72 projections), in each of which counts were collected for $40 \mathrm{~s}$. Reconstruction of the images was performed by filters (order 8; cutoff 0.40 / $\mathrm{cm}$ ) with attenuation correction (Chang method $0.09 / \mathrm{cm}$ ). The matrix size and slice thickness of SPECT images were $128 \times 128$ and $4.3 \mathrm{~mm}$, respectively.

Three-dimensional stereotactic surface projections created with the Neurological Statistical Image Analysis software developed by Minoshima et al. [16] were employed to evaluate the spatial distribution of abnormal perfusion. Each image set was realigned to the bicommissure stereotactic coordinate system [17]. The differences in individual brain size were eliminated by linear scaling, and regional anatomical differences were minimized by a nonlinear warping technique. Each brain was therefore standardized anatomically to match a standard atlas brain while preserving regional perfusion activity. Subsequently, maximum cortical activity was extracted to adjacent predefined surface pixels on a pixel-by-pixel basis using three-dimensional stereotactic surface projections. Data sets were normalized to the mean global activity. To quantify rCBF deficits, the normalized brain activity of each patient was compared with that of 28 normal controls using pixel-by-pixel z-score analysis: (normal mean) - (individual value)/(normal SD). A positive z-score represented a reduced $\mathrm{rCBF}$ in the patient in comparison with the normal control mean.

To demonstrate $\mathrm{rCBF}$ alterations, 2-sample $\mathrm{t}$ test values were calculated on a pixel-bypixel basis between controls and each group on the initial SPECT, and then converted to zvalues by a probability integral transformation. Furthermore, to assess $\mathrm{rCBF}$ changes, intragroup differences between the initial and final SPECT data (after about 32 months) were compared: $\mathrm{AD}$ with $\mathrm{DM}$ group $(\mathrm{n}=11) 32.3 \pm 6.0$ months and $\mathrm{AD}$ without $\mathrm{DM}$ group $(n=12) 31.5 \pm 6.5$ months. Next, to measure rCBF reduction, the mean z-score for each patient was calculated by the stereotactic extraction estimation method [18]. Mean z-scores for each gyrus of the frontal, parietal, temporal, occipital, and limbic lobes of the right and left hemispheres were automatically measured (average $\mathrm{z}$-value of the coordinates with a $\mathrm{z}$-value that exceeded 0 - the threshold value). The mean value in each patient was compared with the corresponding mean values of the 28 control subjects on a region-by-region basis, and 
Table 1. Characteristics of the whole study group

\begin{tabular}{|c|c|c|}
\hline & $\begin{array}{l}\text { AD without DM group } \\
(\mathrm{n}=36)\end{array}$ & $\begin{array}{l}\text { AD with DM group } \\
(\mathrm{n}=35)\end{array}$ \\
\hline Age, years & $78.3 \pm 5.0$ & $79.1 \pm 5.5$ \\
\hline Gender, men/women & $15 / 21$ & $12 / 23$ \\
\hline Education, years & $12.2 \pm 2.9$ & $12.3 \pm 3.0$ \\
\hline Duration of $\mathrm{AD}$, years & $2.5 \pm 0.7$ & $2.2 \pm 1.2$ \\
\hline Initial MMSE score & $21.7 \pm 3.1$ & $21.2 \pm 3.8$ \\
\hline Final MMSE score & $18.7 \pm 4.0^{* * * *}$ & $21.1 \pm 4.5$ \\
\hline Follow-up period, months & $27.7 \pm 4.1$ & $30.1 \pm 8.1$ \\
\hline Fasting plasma glucose, $\mathrm{mg} / \mathrm{dl}$ & $97.5 \pm 6.9^{\#}$ & $152.7 \pm 38.6$ \\
\hline Hemoglobin $A_{1 c} \%$ & $5.3 \pm 0.4^{\# \#}$ & $7.1 \pm 1.6$ \\
\hline \multicolumn{3}{|l|}{ Medication, $\mathrm{n}$ of patients } \\
\hline Donepezil & 35 & 31 \\
\hline DM & 0 & 10 \\
\hline Sulfonylureas & & 8 \\
\hline Biguanides & & 2 \\
\hline$\alpha$-Glucosidase inhibitors & & 2 \\
\hline Thiazolidinediones & & 0 \\
\hline Hypertension & 7 & 10 \\
\hline Hyperlipidemia & 5 & 5 \\
\hline Initial blood pressure, $\mathrm{mm} \mathrm{Hg}$ & $139 \pm 15 / 77 \pm 8$ & $134 \pm 12 / 76 \pm 7$ \\
\hline
\end{tabular}

Values are expressed as means \pm SD or numbers of patients. ${ }^{*} \mathrm{p}<0.05$ vs. initial MMSE score. ${ }^{* *} \mathrm{p}<0.05$ vs. AD with DM group. ${ }^{\#} \mathrm{p}<0.05$ vs. AD with DM group. ${ }^{\# \#} \mathrm{p}<0.05$ vs. AD with DM group.

the reduction in $\mathrm{rCBF}$ was expressed as a $\mathrm{z}$-score. The method of $\mathrm{rCBF}$ measurement was described in detail elsewhere [19].

\section{Statistical Analysis}

Values were expressed as means \pm SD. Statistical analysis was performed using Student's t test, $\chi^{2}$ test, Mann-Whitney $U$ test, and Wilcoxon signed-rank test. A comparison of mean $z$-scores for cerebral subregions between the two groups was performed by one-way ANOVA and post hoc $t$ tests with Bonferroni's corrections. A p value $<0.05$ was considered to indicate a statistically significant difference.

\section{Results}

Patient characteristics of the two groups are summarized in tables 1 and 2. There were no significant differences between the $\mathrm{AD}$ without $\mathrm{DM}$ group and the $\mathrm{AD}$ with $\mathrm{DM}$ group with regard to age, gender, education, duration of symptoms, initial MMSE score, follow-up duration, use of an acetylcholinesterase inhibitor (donepezil), or blood pressure on medical examination. Moreover, age did not significantly differ between patients and controls. The average initial and final MMSE scores were $21.7 \pm 3.0$ and $19.6 \pm 3.5$ in the AD without DM group who were lost for the final SPECT, and $20.8 \pm 3.6$ and $20.3 \pm 3.5$ in the AD with DM group who were lost for the final SPECT, respectively. By definition, although fasting plasma glucose and hemoglobin $\mathrm{A}_{1 \mathrm{c}}$ levels were normal in the $\mathrm{AD}$ without $\mathrm{DM}$ group, they were higher in the $\mathrm{AD}$ with $\mathrm{DM}$ group. MMSE scores at the final evaluation were significantly lower compared with the initial evaluation in the $\mathrm{AD}$ without $\mathrm{DM}$ group, but not in the $\mathrm{AD}$ 
Table 2. Characteristics of the patients presenting at the final follow-up

\begin{tabular}{|c|c|c|}
\hline & $\begin{array}{l}\text { AD without } \mathrm{DM} \\
\text { group }(\mathrm{n}=12)\end{array}$ & $\begin{array}{l}\text { AD with DM } \\
\text { group }(n=11)\end{array}$ \\
\hline Age, years & $78.9 \pm 4.6$ & $77.9 \pm 6.3$ \\
\hline Gender, men/women & $6 / 6$ & $5 / 6$ \\
\hline Education, years & $12.3 \pm 3.3$ & $11.8 \pm 2.9$ \\
\hline Duration of $\mathrm{AD}$, years & $2.4 \pm 0.9$ & $2.0 \pm 0.8$ \\
\hline Initial MMSE score & $22.5 \pm 2.8$ & $22.3 \pm 3.8$ \\
\hline Final MMSE score & $17.4 \pm 4.6^{* * *}$ & $21.7 \pm 5.1$ \\
\hline Initial fasting plasma glucose, $\mathrm{mg} / \mathrm{dl}$ & $97.7 \pm 7.0^{\#}$ & $138.0 \pm 26.0$ \\
\hline Final fasting plasma glucose, $\mathrm{mg} / \mathrm{dl}$ & $107 \pm 22^{\# \#}$ & $132 \pm 23$ \\
\hline Initial hemoglobin $\mathrm{A}_{1 \mathrm{c}}, \%$ & $4.8 \pm 0.3^{\# \# \#}$ & $7.0 \pm 1.8$ \\
\hline Final hemoglobin $\mathrm{A}_{1 \mathrm{c}}, \%$ & & $6.5 \pm 0.9$ \\
\hline \multicolumn{3}{|l|}{ Duration of DM } \\
\hline$\leq 3$ years & & 7 \\
\hline $3-10$ years & & 0 \\
\hline $10-20$ years & & 4 \\
\hline$>20$ years & & 0 \\
\hline \multicolumn{3}{|l|}{ Duration of anti-DM medication } \\
\hline$\leq 3$ years & & 6 \\
\hline $3-10$ years & & 1 \\
\hline$>10$ years & & 3 \\
\hline Type of DM medication during follow-up & & 5 \\
\hline Sulfonylureas & & 1 \\
\hline Biguanides & & 2 \\
\hline$\alpha$-Glucosidase inhibitors & & 1 \\
\hline Thiazolidinediones & & 3 \\
\hline Initial blood pressure score & $136 \pm 17 / 76 \pm 8$ & $136 \pm 17 / 76 \pm 7$ \\
\hline Final blood pressure score & $127 \pm 11 / 76 \pm 9$ & $138 \pm 16 / 75 \pm 8$ \\
\hline \multicolumn{3}{|l|}{ Medication, $\mathrm{n}$ of patients } \\
\hline Hypertension & 2 & 5 \\
\hline Calcium channel blockers & 2 & 4 \\
\hline Angiotensin-converting enzyme inhibitors & 0 & 1 \\
\hline Angiotensin-2 receptor blockers & 0 & 0 \\
\hline Hyperlipidemia & 2 & 4 \\
\hline Statins & 1 & 3 \\
\hline \multicolumn{3}{|c|}{$\begin{array}{l}\text { Values are expressed as means } \pm \text { SD or numbers of patients. } \\
{ }^{*} \mathrm{p}<0.05 \text { vs. initial MMSE score. }{ }^{* *} \mathrm{p}<0.05 \text { vs. AD with DM group. }{ }^{\#} \mathrm{p}<0.05 \text { vs. AD with DM } \\
\text { group. }{ }^{\# \#} \mathrm{p}<0.05 \text { vs. AD with DM group. }{ }^{\# \#} \mathrm{p}<0.05 \text { vs. AD with DM group. }\end{array}$} \\
\hline
\end{tabular}

with DM group. As illustrated by table 2, the final hemoglobin $A_{1 c}$ levels were lower than the initial levels, but the difference was only significant in the AD without DM group.

In table 3, qualitative MRI parameters are compared. There were no significant differences between the $20 \mathrm{AD}$ patients without $\mathrm{DM}$ and the $22 \mathrm{AD}$ patients with $\mathrm{DM}$ in terms of periventricular $\left(\chi^{2}=1.43\right.$, d.f. $\left.=2\right)$ and deep white matter hyperintensity lesions $\left(\chi^{2}=0.05\right.$, d.f. $=2)$ or lacunar infarctions $\left(\chi^{2}=3.35\right.$, d.f. $\left.=2\right)$. Sixteen patients without DM and 13 patients with DM in whom only brain CT was performed had no abnormal high- or low-density lesions in their parenchyma.

Figure la and $\mathrm{b}$ presents the relative decrease in $\mathrm{rCBF}$ in the $\mathrm{AD}$ without $\mathrm{DM}$ group and in the $\mathrm{AD}$ with $\mathrm{DM}$ group compared with normal controls on the initial SPECT, respectively. Both groups showed significant decreases in $\mathrm{rCBF}$ in the parietotemporal lobes, posterior 
Table 3. Qualitative MRI analysis results

\begin{tabular}{lcl}
\hline & $\begin{array}{l}\text { AD without DM group } \\
(\mathrm{n}=20)\end{array}$ & $\begin{array}{l}\text { AD with DM group } \\
(\mathrm{n}=22)\end{array}$ \\
\hline \multicolumn{2}{l}{ White matter lesions } \\
Periventricular hyperintensity lesions \\
0 & \\
1 & 11 & \\
2 & 6 & 16 \\
Deep white matter hyperintensity lesions & \\
0 & 13 & 2 \\
1 & 5 & 15 \\
2 & 2 & 5 \\
\hline Lacunar infarctions & 2 \\
No & 12 & \\
Single & 4 & 14 \\
multiple & 4 & 7 \\
\hline
\end{tabular}

cingulate and cinguloparietal transitional areas, and frontal association cortices, and these decreases are considered characteristic features of AD. Figure 1c compares three-dimensional views of decreased $\mathrm{rCBF}$ between $\mathrm{AD}$ patients with and without DM. Statistical mapping demonstrated that regions with decreased $\mathrm{rCBF}$ included the left and right inferior temporal gyri in the $\mathrm{AD}$ without $\mathrm{DM}$ group compared with the $\mathrm{AD}$ with $\mathrm{DM}$ group. However, the $\mathrm{AD}$ with $\mathrm{DM}$ group had no significantly decreased $\mathrm{rCBF}$ areas compared with the $\mathrm{AD}$ without DM group.

Figure $2 \mathrm{a}$ and $\mathrm{b}$ presents $\mathrm{rCBF}$ changes between initial and final SPECT in both groups. In the $\mathrm{AD}$ without $\mathrm{DM}$ group $\mathrm{rCBF}$ was decreased in the temporoparietal and cingulate gyri of the right and left hemispheres. In contrast, in the AD with DM group rCBF was decreased in small and scattered regions of the right and left hemispheres, including the anterior cingulate region. Both groups showed improvement in $\mathrm{rCBF}$ levels in some regions of the frontal and medial occipital lobes, and in the cerebellum.

Mean z-scores for the cerebral subregions on the initial and final SPECT were compared in the two groups (table 4). On the initial SPECT, z-scores for the left inferior temporal gyrus were significantly higher in the $\mathrm{AD}$ without $\mathrm{DM}$ group than in the $\mathrm{AD}$ with $\mathrm{DM}$ group. In comparison with the initial SPECT, the final SPECT showed significantly higher z-scores in widespread regions, including the frontal, parietal, temporal, and limbic lobes of the AD without DM group, and in the right anterior cingulate region of the $\mathrm{AD}$ with $\mathrm{DM}$ group. Neither group had significantly lower z-scores in any regions on the final SPECT compared with the initial SPECT.

\section{Discussion}

We found that the $\mathrm{AD}$ without $\mathrm{DM}$ group had greater $\mathrm{rCBF}$ deficits at the initial evaluation in the left and right inferior temporal gyri than the AD with DM group, even though both had comparable MMSE scores and duration of symptoms. According to the study of Delacourte et al. [20], neurofibrillary degeneration with paired helical filament tau was systematically present and patients at the first stage of $\mathrm{AD}$ had large amounts of paired helical filament tau in the temporal cortex. Considering such findings, the higher hypoperfusion in 


\section{Dementia
and Geriatric
Cognitive Disorders}

\begin{tabular}{l|l}
\hline \multicolumn{2}{l}{ Dement Geriatr Cogn Disord Extra 2011;1:62-74 } \\
\hline DOI: 10.1159/000323865 & $\begin{array}{l}\text { @ } 2011 \text { S. Karger AG, Basel } \\
\text { www.karger.com/dee }\end{array}$ \\
Published online: January 27, 2011 &
\end{tabular}

Hirao et al.: rCBF Patterns in AD with or without DM

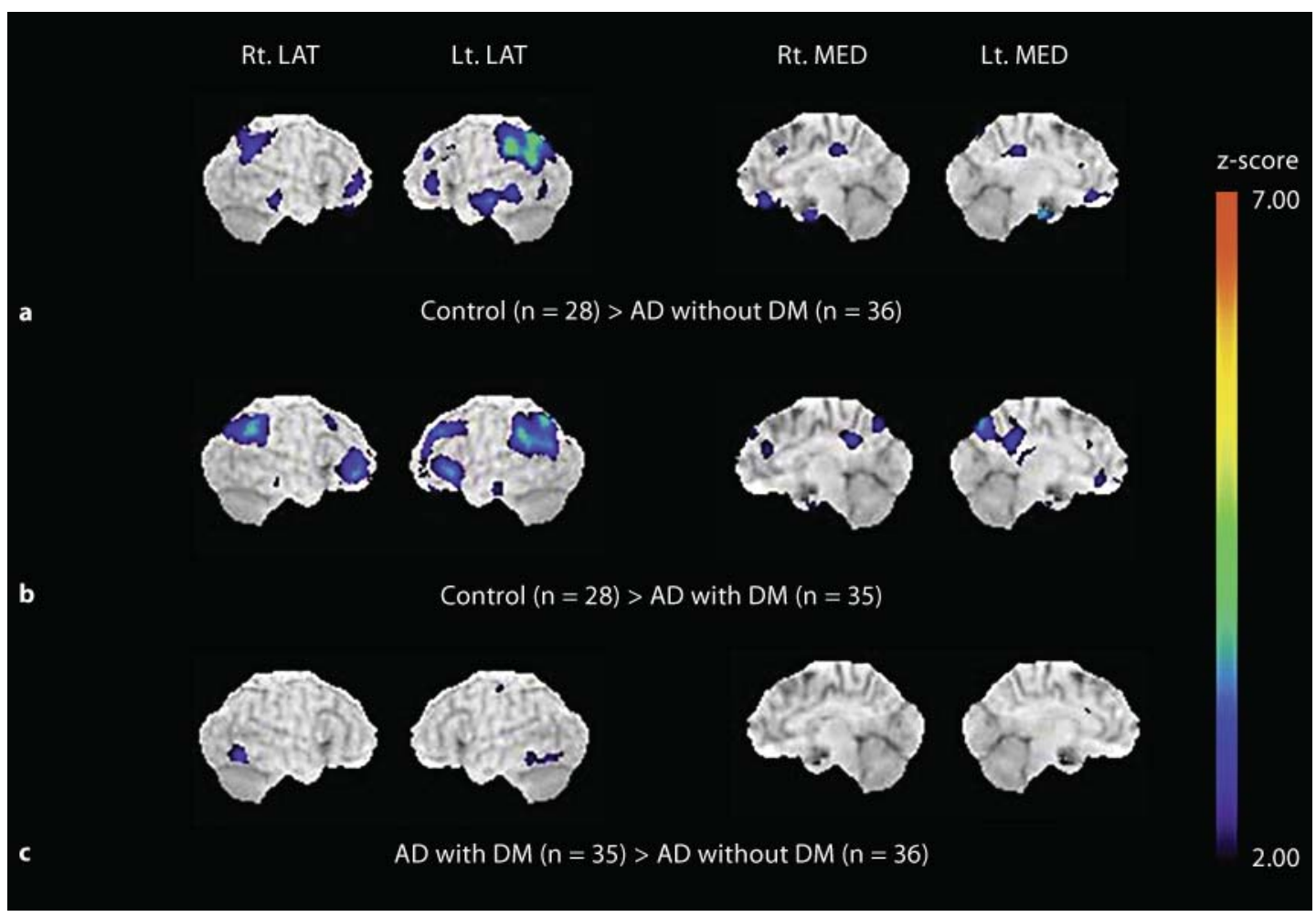

Fig. 1. Statistical maps showing the relative decrease in $\mathrm{rCBF}$ in the $\mathrm{AD}$ without $\mathrm{DM}$ group and $\mathrm{AD}$ with DM group.

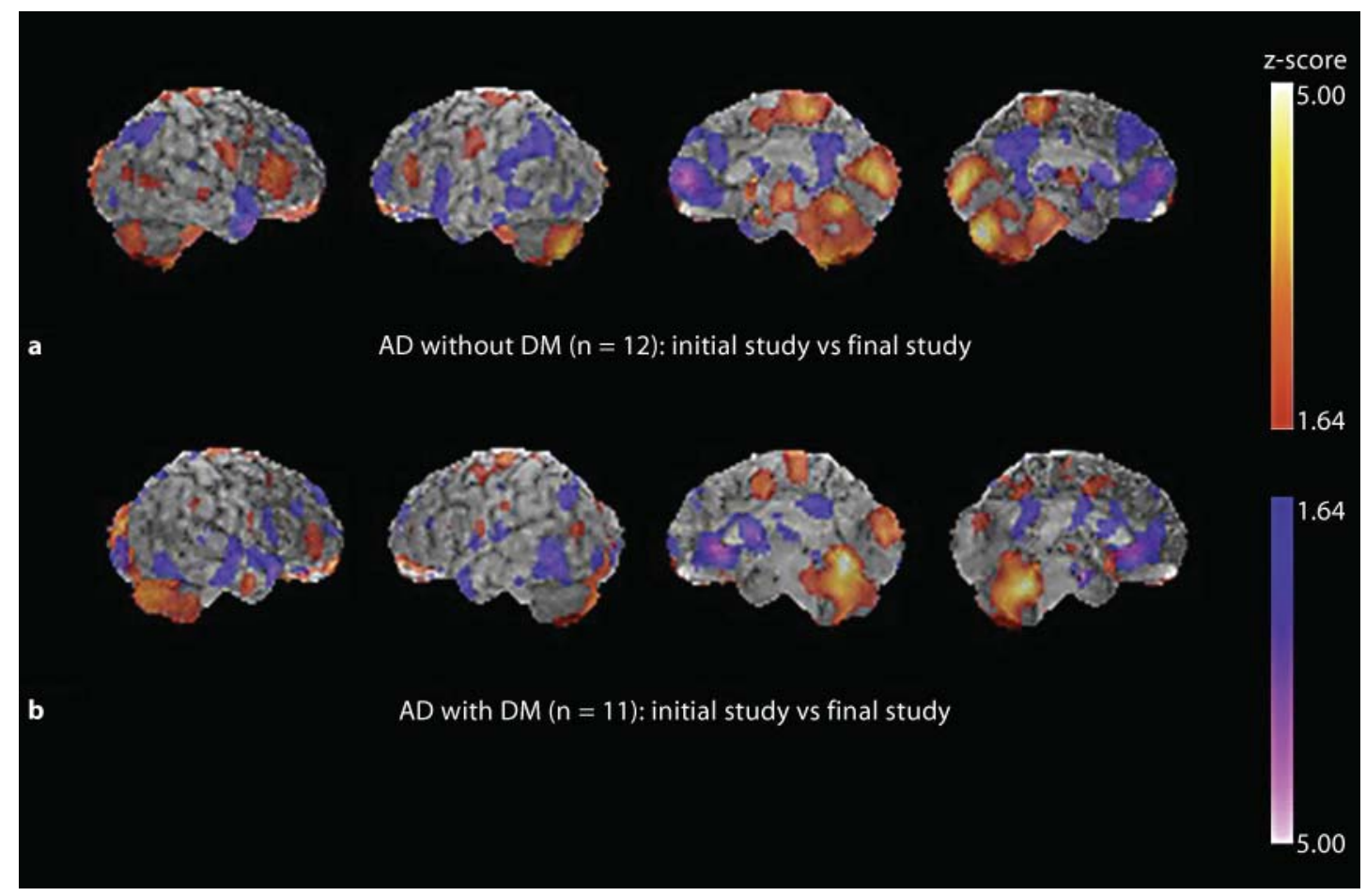

Fig. 2. Statistical maps showing the relative changes on repeated SPECT in the AD without DM group and $\mathrm{AD}$ with $\mathrm{DM}$ group. The red scale indicates the relative $\mathrm{CCBF}$ increase, and the blue scale the relative $\mathrm{rCBF}$ decrease. 
Table 4. Results of $z$-scores for each cerebral subregion on initial and final SPECT

\begin{tabular}{|c|c|c|c|c|c|}
\hline & & \multicolumn{2}{|c|}{ AD without DM group } & \multicolumn{2}{|c|}{ AD with DM group } \\
\hline & & baseline & month 32 & baseline & month 32 \\
\hline \multicolumn{6}{|l|}{ Frontal lobe } \\
\hline \multirow[t]{2}{*}{ Superior frontal gyrus } & $\mathrm{L}$ & $1.03 \pm 0.37$ & $1.11 \pm 0.34$ & $0.93 \pm 0.41$ & $1.02 \pm 0.58$ \\
\hline & $\mathrm{R}$ & $0.93 \pm 0.40$ & $0.99 \pm 0.43$ & $0.93 \pm 0.47$ & $1.05 \pm 0.62$ \\
\hline \multirow{2}{*}{ Middle frontal gyrus } & $\mathrm{L}$ & $1.06 \pm 0.34$ & $1.25 \pm 0.50$ & $1.01 \pm 0.44$ & $1.05 \pm 0.75$ \\
\hline & $\mathrm{R}$ & $1.10 \pm 0.47$ & $1.12 \pm 0.55$ & $0.96 \pm 0.41$ & $0.97 \pm 0.51$ \\
\hline \multirow[t]{2}{*}{ Inferior frontal gyrus } & $\mathrm{L}$ & $1.06 \pm 0.44$ & $1.32 \pm 0.78$ & $1.19 \pm 0.47$ & $1.26 \pm 0.80$ \\
\hline & $\mathrm{R}$ & $0.86 \pm 0.47$ & $0.91 \pm 0.38$ & $0.79 \pm 0.32$ & $0.87 \pm 0.32$ \\
\hline \multirow[t]{2}{*}{ Medial frontal gyrus } & $\mathrm{L}$ & $1.02 \pm 0.36$ & $1.18 \pm 0.36$ & $0.95 \pm 0.42$ & $1.09 \pm 0.54$ \\
\hline & $\mathrm{R}$ & $0.96 \pm 0.32$ & $1.19 \pm 0.53^{*}$ & $1.03 \pm 0.47$ & $1.11 \pm 0.65$ \\
\hline \multirow[t]{2}{*}{ Orbital gyrus } & $\mathrm{L}$ & $0.83 \pm 1.02$ & $1.47 \pm 1.02$ & $0.94 \pm 0.81$ & $1.02 \pm 0.97$ \\
\hline & $\mathrm{R}$ & $1.45 \pm 1.27$ & $1.22 \pm 0.76$ & $0.70 \pm 0.68$ & $0.95 \pm 1.10$ \\
\hline \multirow[t]{2}{*}{ Rectal gyrus } & $\mathrm{L}$ & $0.98 \pm 0.73$ & $1.22 \pm 0.74$ & $0.89 \pm 0.35$ & $0.83 \pm 0.66$ \\
\hline & $\mathrm{R}$ & $0.80 \pm 0.45$ & $1.20 \pm 0.61$ & $0.73 \pm 0.42$ & $0.73 \pm 0.56$ \\
\hline \multirow[t]{2}{*}{ Paracentral lobule } & $\mathrm{L}$ & $0.40 \pm 0.48$ & $0.71 \pm 0.61^{*}$ & $0.57 \pm 0.42$ & $0.61 \pm 0.31$ \\
\hline & $\mathrm{R}$ & $0.46 \pm 0.34$ & $0.51 \pm 0.43$ & $0.45 \pm 0.36$ & $0.59 \pm 0.21$ \\
\hline \multirow[t]{2}{*}{ Precentral gyrus } & $\mathrm{L}$ & $0.81 \pm 0.27$ & $0.89 \pm 0.35$ & $0.70 \pm 0.17$ & $0.76 \pm 0.32$ \\
\hline & $\mathrm{R}$ & $0.73 \pm 0.23$ & $0.78 \pm 0.29$ & $0.62 \pm 0.27$ & $0.67 \pm 0.27$ \\
\hline \multirow{2}{*}{ Subcallosal gyrus } & $\mathrm{L}$ & $0.99 \pm 0.60$ & $0.99 \pm 0.41$ & $0.77 \pm 0.48$ & $0.69 \pm 0.38$ \\
\hline & $\mathrm{R}$ & $0.52 \pm 0.31$ & $0.68 \pm 0.42$ & $0.61 \pm 0.59$ & $0.68 \pm 0.34$ \\
\hline \multicolumn{6}{|l|}{ Parietal lobe } \\
\hline \multirow[t]{2}{*}{ Superior parietal lobule } & $\mathrm{L}$ & $1.12 \pm 0.49$ & $1.34 \pm 0.75$ & $1.05 \pm 0.22$ & $1.02 \pm 0.27$ \\
\hline & $\mathrm{R}$ & $0.89 \pm 0.50$ & $1.07 \pm 0.63$ & $0.93 \pm 0.12$ & $1.01 \pm 0.75$ \\
\hline \multirow{2}{*}{ Inferior parietal lobule } & $\mathrm{L}$ & $1.35 \pm 0.76$ & $1.72 \pm 0.90^{*}$ & $1.33 \pm 0.83$ & $1.32 \pm 0.84$ \\
\hline & $\mathrm{R}$ & $1.02 \pm 0.59$ & $1.43 \pm 0.96^{*}$ & $1.08 \pm 0.70$ & $1.29 \pm 0.86$ \\
\hline \multirow[t]{2}{*}{ Angular gyrus } & $\mathrm{L}$ & $1.20 \pm 0.56$ & $1.76 \pm 1.09^{*}$ & $1.35 \pm 0.76$ & $1.33 \pm 0.97$ \\
\hline & & $0.74 \pm 0.88$ & $1.44 \pm 1.24^{*}$ & $1.22 \pm 1.06$ & $1.38 \pm 1.19$ \\
\hline \multirow[t]{2}{*}{ Postcentral gyrus } & $\mathrm{L}$ & $0.95 \pm 0.51$ & $0.88 \pm 0.48$ & $0.76 \pm 0.37$ & $0.79 \pm 0.31$ \\
\hline & $\mathrm{R}$ & $0.83 \pm 0.33$ & $0.78 \pm 0.59$ & $0.72 \pm 0.27$ & $0.83 \pm 0.37$ \\
\hline \multirow[t]{2}{*}{ Precuneus } & $\mathrm{L}$ & $0.83 \pm 0.40$ & $1.15 \pm 0.67$ & $1.15 \pm 0.66$ & $1.14 \pm 0.55$ \\
\hline & $\mathrm{R}$ & $0.70 \pm 0.51$ & $0.95 \pm 0.69$ & $0.95 \pm 0.47$ & $1.12 \pm 0.54$ \\
\hline Supramarginal gyrus & $\mathrm{L}$ & $1.36 \pm 0.78$ & $1.90 \pm 1.15$ & $1.58 \pm 0.94$ & $1.44 \pm 1.21$ \\
\hline & $\mathrm{R}$ & $0.89 \pm 0.68$ & $1.29 \pm 1.12^{*}$ & $1.37 \pm 0.92$ & $1.28 \pm 1.14$ \\
\hline Temporal lobe & & & & & \\
\hline Superior temporal gyrus & $\mathrm{L}$ & $1.08 \pm 0.38$ & $1.34 \pm 0.54$ & $0.91 \pm 0.17$ & $1.04 \pm 0.52$ \\
\hline & $\mathrm{R}$ & $0.91 \pm 0.52$ & $1.33 \pm 0.70^{*}$ & $0.80 \pm 0.38$ & $0.95 \pm 0.38$ \\
\hline Middle temporal gyrus & $\mathrm{L}$ & $1.13 \pm 0.39$ & $1.47 \pm 0.73^{*}$ & $1.00 \pm 0.41$ & $1.16 \pm 0.52$ \\
\hline & $\mathrm{R}$ & $0.92 \pm 0.78$ & $1.24 \pm 0.98^{*}$ & $0.86 \pm 0.22$ & $0.95 \pm 0.35$ \\
\hline Inferior temporal gyrus & $\mathrm{L}$ & $1.37 \pm 0.81^{\#}$ & $1.45 \pm 1.05$ & $0.95 \pm 0.26$ & $1.21 \pm 0.51$ \\
\hline & $\mathrm{R}$ & $1.12 \pm 0.73$ & $1.25 \pm 0.80$ & $0.91 \pm 0.29$ & $1.13 \pm 0.49$ \\
\hline Transverse temporal gyrus & $\mathrm{L}$ & $0.39 \pm 0.59$ & $0.54 \pm 0.73$ & $0.49 \pm 0.45$ & $0.56 \pm 0.66$ \\
\hline & $\mathrm{R}$ & $0.39 \pm 0.45$ & $0.40 \pm 0.48$ & $0.29 \pm 0.47$ & $0.40 \pm 0.55$ \\
\hline Occipital lobe & & & & & \\
\hline Superior occipital gyrus & $\mathrm{L}$ & $1.05 \pm 0.96$ & $1.17 \pm 0.97$ & $0.80 \pm 0.46$ & $0.60 \pm 0.40$ \\
\hline & $\mathrm{R}$ & $0.91 \pm 0.96$ & $1.06 \pm 1.08$ & $0.85 \pm 0.81$ & $0.82 \pm 1.02$ \\
\hline Middle occipital gyrus & $\mathrm{L}$ & $1.17 \pm 0.87$ & $1.49 \pm 1.15$ & $0.81 \pm 0.33$ & $0.93 \pm 0.47$ \\
\hline & $\mathrm{R}$ & $1.08 \pm 0.84$ & $1.25 \pm 1.10$ & $0.66 \pm 0.46$ & $0.91 \pm 0.74$ \\
\hline Inferior occipital gyrus & $\mathrm{L}$ & $0.60 \pm 0.50$ & $0.84 \pm 0.68$ & $0.51 \pm 0.46$ & $0.50 \pm 0.45$ \\
\hline & $\mathrm{R}$ & $0.85 \pm 0.68$ & $0.83 \pm 0.92$ & $0.65 \pm 0.53$ & $0.70 \pm 0.75$ \\
\hline Cuneus & $\mathrm{L}$ & $0.89 \pm 0.63$ & $0.76 \pm 0.48$ & $0.75 \pm 0.34$ & $0.76 \pm 0.43$ \\
\hline & $\mathrm{R}$ & $0.72 \pm 0.60$ & $0.70 \pm 0.42$ & $0.68 \pm 0.37$ & $0.65 \pm 0.60$ \\
\hline Fusiform gyrus & $\mathrm{L}$ & $1.53 \pm 0.84$ & $1.46 \pm 0.98$ & $0.80 \pm 0.38$ & $1.19 \pm 0.56$ \\
\hline & $\mathrm{R}$ & $1.07 \pm 0.62$ & $1.28 \pm 0.74$ & $0.71 \pm 0.26$ & $1.01 \pm 0.48$ \\
\hline Lingual gyrus & $\mathrm{L}$ & $0.62 \pm 0.75$ & $0.38 \pm 0.32$ & $0.54 \pm 0.43$ & $0.67 \pm 0.50$ \\
\hline & $\mathrm{R}$ & $0.58 \pm 0.55$ & $0.44 \pm 0.59$ & $0.50 \pm 0.70$ & $0.42 \pm 0.45$ \\
\hline
\end{tabular}


Table 4 (continued)

\begin{tabular}{|c|c|c|c|c|c|}
\hline & & \multicolumn{2}{|c|}{ AD without DM group } & \multicolumn{2}{|c|}{ AD with DM group } \\
\hline & & baseline & month 32 & baseline & month 32 \\
\hline \multicolumn{6}{|l|}{ Limbic lobe } \\
\hline \multirow[t]{2}{*}{ Thalamus } & $\mathrm{L}$ & $0.25 \pm 0.27$ & $0.24 \pm 0.38$ & $0.26 \pm 0.18$ & $0.32 \pm 0.30$ \\
\hline & $\mathrm{R}$ & $0.25 \pm 0.31$ & $0.29 \pm 0.34$ & $0.28 \pm 0.26$ & $0.37 \pm 0.54$ \\
\hline \multirow[t]{2}{*}{ Cingulate gyrus } & $\mathrm{L}$ & $0.84 \pm 0.35$ & $1.16 \pm 0.23^{*}$ & $0.85 \pm 0.33$ & $1.06 \pm 0.26$ \\
\hline & $\mathrm{R}$ & $0.83 \pm 0.31$ & $1.00 \pm 0.23^{*}$ & $0.80 \pm 0.36$ & $1.01 \pm 0.24$ \\
\hline \multirow[t]{2}{*}{ Parahippocampal gyrus } & $\mathrm{L}$ & $1.22 \pm 0.42$ & $1.14 \pm 0.64$ & $0.77 \pm 0.54$ & $0.92 \pm 0.50$ \\
\hline & $\mathrm{R}$ & $0.66 \pm 0.31$ & $0.91 \pm 0.44$ & $0.71 \pm 0.36$ & $0.81 \pm 0.54$ \\
\hline \multirow[t]{2}{*}{ Anterior cingulate gyrus } & $\mathrm{L}$ & $0.96 \pm 0.43$ & $1.27 \pm 0.58^{*}$ & $0.96 \pm 0.31$ & $1.22 \pm 0.62$ \\
\hline & $\mathrm{R}$ & $0.83 \pm 0.42$ & $1.13 \pm 0.49$ & $0.87 \pm 0.34$ & $1.16 \pm 0.46^{*}$ \\
\hline \multirow[t]{2}{*}{ Posterior cingulate gyrus } & $\mathrm{L}$ & $0.84 \pm 0.50$ & $1.12 \pm 0.42$ & $1.00 \pm 0.54$ & $1.07 \pm 0.57$ \\
\hline & $\mathrm{R}$ & $0.69 \pm 0.52$ & $0.87 \pm 0.37$ & $0.74 \pm 0.47$ & $0.95 \pm 0.56$ \\
\hline \multirow[t]{2}{*}{ Uncus } & $\mathrm{L}$ & $1.50 \pm 0.67$ & $1.54 \pm 1.06$ & $0.86 \pm 0.47$ & $1.08 \pm 0.66$ \\
\hline & $\mathrm{R}$ & $0.98 \pm 0.42$ & $0.82 \pm 0.49$ & $0.82 \pm 0.39$ & $1.03 \pm 0.60$ \\
\hline
\end{tabular}

the left and right inferior temporal gyri may reflect more severe neuronal degeneration by AD pathology. Moreover, compared with the initial SPECT, in the follow-up SPECT, rCBF in the $\mathrm{AD}$ without $\mathrm{DM}$ group was significantly reduced in widespread regions, including the parietal, temporal, frontal, and limbic lobes, whereas it was significantly reduced only in the anterior cingulate region in the $\mathrm{AD}$ with $\mathrm{DM}$ group. Our results suggest that functional brain abnormalities of $\mathrm{AD}$ differ depending on DM status at baseline and during follow-up.

Some investigators have examined the relation of DM with the neuropathologic features of $\mathrm{AD}$, including neuritic plaques and neurofibrillary tangles, but the results were inconclusive [21-25]. One study only found an association (with the $\varepsilon 4$ allele) in a subgroup of individuals with DM [21], whereas others failed to demonstrate an association between DM and the histopathologic features of AD [22-24]. Beeri et al. [25] found that DM was associated with less AD neuropathology. However, Launer [26] reported that, compared with non-DM individuals, those with DM have structural brain changes that reflect neuronal degeneration as well as vascular damage, and it is likely that DM leads to microstructural changes not observed on MRI. Therefore, we assume that microvascular abnormalities may more strongly affect the pattern of $\mathrm{rCBF}$ deficits in the $\mathrm{AD}$ with $\mathrm{DM}$ group than in the $\mathrm{AD}$ without $\mathrm{DM}$ group, although our MRI study demonstrated that the involvement of the damaged white matter and the number of lacunar infarctions were not significantly different in the two groups. In a recent study, Sonnen et al. [27] observed two patterns of cerebral damage in patients with dementia according to DM status. In non-DM individuals, dementia was associated with a greater $A \beta$ burden, whereas in DM individuals, dementia was associated with more microvascular infarctions. A recent clinical cohort study revealed that cognitive decline during follow-up was faster in $\mathrm{AD}$ alone than in $\mathrm{AD}$ combined with cerebrovascular disease [28]. In the present study, the $\mathrm{AD}$ with $\mathrm{DM}$ group had less $\mathrm{rCBF}$ deficits in the inferior temporal gyrus on the initial SPECT and we consider that they had slower cognitive decline than the $\mathrm{AD}$ without $\mathrm{DM}$ group during the follow-up time, even though the MMSE scores and duration of disease were comparable on the initial SPECT, because they may have had brain damage, including microvascular or metabolic abnormalities intrinsic to DM, but with less $\mathrm{AD}$ neuropathology than the $\mathrm{AD}$ without $\mathrm{DM}$ group. 
Several studies have examined the effect of DM on the rate of cognitive decline [6-10]. However, the results are controversial; some found faster [6] or slower $[7,8]$ cognitive decline in $\mathrm{AD}$ patients with $\mathrm{DM}$, or even no effects of $\mathrm{DM}$ on the rate of cognitive decline $[9,10]$. Although the Rotterdam study reported the effects of antidiabetic medication on the pathogenesis of clinical AD [29], the Sacramento Area Latino Study on Aging (SALSA) illustrated that antidiabetic drugs appear to be useful for alleviating cognitive decline among individuals with DM, especially for those with a longer duration of disease [30]. A recent study in a large autopsy cohort demonstrated that the combination of insulin with other DM medication is associated with less AD neuropathology [31]. In this study, about $36 \%$ of the subjects had DM for $>10$ years, and in about $64 \%$ of the subjects DM was diagnosed within the last 3 years. Because $>60 \%$ of patients were relatively newly diagnosed, we cannot discount the possibility that the $\mathrm{AD}$ with $\mathrm{DM}$ group in our study is not representative of the entire $\mathrm{DM}$ population and thus carries a survival advantage which may be associated with a less aggressive cognitive decline. Insulin-sensitizing agents, such as rosiglitazone and pioglitazone (agonists of PPAR $\gamma$ ), have been shown to inhibit inflammatory gene expression, alter A $\beta$ homeostasis, and exhibit neuroprotective effects. Recent clinical trials have found that agonists of PPAR $\gamma$ improve cognition and memory in AD patients [32]. In the present study, PPAR $\gamma$ agonists might have affected $\mathrm{rCBF}$ changes because 3 of the $11 \mathrm{AD}$ patients with DM during the follow-up period were given thiazolidinediones after the initial SPECT. In addition, antihypertensive drugs and statins, which were more frequently administered in DM patients than in non-DM subjects, may offer some therapeutic relief for AD patients. Recent studies have found evidence that some antihypertensive medications, including calcium channel blockers [33], angiotensin-converting enzyme inhibitors [34], angiotensin-2 receptor blockers [35] and statins [36], prevent the incidence of $\mathrm{AD}$, reduce cognitive decline, and are associated with less severe AD pathology. These findings explain the slower rate of cognitive and functional decline in patients with DM. However, it is unlikely that antihypertensive medications and statins had any effects in the present study, because the blood pressure data in both groups were good at the initial and final evaluation, and hypertensive medication did not significantly differ between the initial and final evaluation.

Our study has some limitations. First, follow-up SPECT was only obtained in one third of the patients (12 patients without DM and 11 patients with DM), which raises the possibility that patients with dramatic deterioration of dementia were lost to follow-up SPECT. However, patients included in the follow-up SPECT are possibly representative of the entire population, since their clinical and demographic characteristics were comparable to those of the entire cohort. Despite the relatively small study cohort, there were clear differences in rCBF decline between patients with and without DM. Second, this study lacked non-demented DM subjects as a control group. We believe that the comparison of $\mathrm{rCBF}$ in the AD with $\mathrm{DM}$ group with the non-demented DM subjects was necessary in order to closely investigate rCBF patterns in the AD with $\mathrm{DM}$ group, because $\mathrm{rCBF}$ patterns may differ between nondemented DM patients and normal controls. Third, although our AD diagnosis was not neuropathologically confirmed, neuroimaging studies were used as part of the diagnostic process. In particular, $\mathrm{rCBF}$ reductions in the parietotemporal association cortex on SPECT are recognized as a diagnostic pattern for $\mathrm{AD}$, and SPECT provides a higher specificity for other types of dementia than clinical criteria [37]. As our patients presented characteristic features of $\mathrm{rCBF}$ patterns in $\mathrm{AD}$ on baseline SPECT, we feel confident that all cases in the present series of $\mathrm{AD}$ did indeed have AD. Fourth, it remains uncertain whether MMSE is the more appropriate instrument for assessing cognitive decline in $\mathrm{AD}$. Although disease severity was measured using MMSE in this study, a single measurement may be an imperfect index of the rate of change in symptoms over an extended period. Be that as it may, a recent study revealed that the validity of measurements of the rate of change in MMSE was reliable 
when observations were separated by 3 years or more [38]. As we followed up our patients for 24-48 months, the rate of cognitive decline is likely to be a reliable parameter for assessing the cognitive decline in AD. Fifth, although the present analysis assumes a constant rate of decline, the rate of decline in neuropsychologic function can be quite variable. MMSE scores may plateau, especially in the very early stages of AD. Since our patients had mild-to-moderate stages defined by a mean MMSE score of approximately 21 at the initial evaluation, most patients may have a relatively steady course of cognitive decline. Furthermore, almost all patients in this study were treated with donepezil, which may slow the clinical progression of $\mathrm{AD}$. Therefore, the rate of cognitive decline in our patients may be different from that in patients who never used cholinesterase inhibitors. Thus, the effect of medication on clinical progression should be taken into consideration, since the majority of patients examined in this study have been treated with a cholinesterase inhibitor.

\section{Conclusion}

In the initial SPECT, a lower $\mathrm{rCBF}$ in the left and right inferior temporal gyri was observed in the $\mathrm{AD}$ without $\mathrm{DM}$ group than in the $\mathrm{AD}$ with $\mathrm{DM}$ group. A follow-up SPECT showed that, in the $\mathrm{AD}$ without $\mathrm{DM}$ group, $\mathrm{rCBF}$ decreased in more widespread regions, including the parietal, temporal, frontal, and limbic lobes, than in the AD with DM group. Functional brain abnormalities in $\mathrm{AD}$ may differ depending on the $\mathrm{DM}$ status at baseline and during follow-up, reflecting neuropathologic differences.

\section{Acknowledgments}

We thank Prof. K. Koizumi of the Department of Nuclear Medicine of Tokyo Medical University for his support and technical assistance. We are also grateful to Assistant Prof. Edward F. Barroga and Prof. J. Patrick Barron of the Department of International Medical Communications of Tokyo Medical University for their review of the paper.

\section{Disclosure Statement}

The authors have no conflicts of interest.

\section{References}

1 Biessels GJ, Staekenborg S, Brunner E, Brayne C, Scheltens P: Risk of dementia in diabetic mellitus: a systemic review. Lancet Neurol 2006;5:64-74.

2 Craft S, Watson S: Insulin and neurodegenerative disease: shared and specific mechanisms. Lancet Neurol 2004;3:169-178.

3 Neumann KF, Rojo L, Navarrete LP, Farias G, Reyes P, Maccioni RB: Insulin resistance and Alzheimer's disease: molecular links and clinical implications. Curr Alzheimer Res 2008;5:438-447.

4 den Heijer T, Vermeer SE, van Dijk EJ, Prins ND, Koudstaal PJ, Hofman A, Breteler MM: Type 2 diabetes and atrophy of medial temporal lobe structures on brain MRI. Diabetologia 2003;46:16041610 .

5 Schmidt R, Launer LJ, Nilsson LG, Pajak A, Sans S, Berger K, Breteler MM, de Ridder M, Dufouil C, Fuhrer R, Giampaoli S, Hofman A: Magnetic resonance imaging of the brain in diabetes. The Cardiovascular Determinants of Dementia (CASCADE) Study. Diabetes 2004;53:687-692. 
6 Helzner EP, Luchsinger JA, Scarmeas N, Cosentino S, Brickman AM, Glymour MM, Stern Y, Gertrude $\mathrm{H}$ : Contribution of vascular risk factors to the progression in Alzheimer disease. Arch Neurol 2009;66:343-348.

7 Mielke MM, Rosenberg PB, Tschanz J, Cook L, Corcoran C, Hayden KM, Norton M, Rabins PV, Green RC, Welsh-Bohmer KA, Breitner JC, Munger R, Lyketsos CG: Vascular factors predict rate of progression in Alzheimer disease. Neurology 2007;69:1850-1858.

8 Sanz C, Andrieu S, Sinclair A, Hanaire H, Vellas B, the REAL.FR Study Group: Diabetes is associated with a slower rate of cognitive decline in Alzheimer disease. Neurology 2009;73:1359-1366.

9 van Kan GA, Rolland Y, Nourhashemi F, Coley N, Andrieu S, Vellas B: Cardiovascular disease risk factors and progression of Alzheimer's disease. Dement Geriatr Cogn Disord 2009;27:240-246.

10 Regan C, Katona C, Walker Z, Hooper J, Donovan J, Livingston G: Relationship of vascular risk to the progression of Alzheimer disease. Neurology 2006;67:1357-1362.

11 McKhann G, Drachman D, Folstein M, Katzman R, Price D, Stadlan EM: Clinical diagnosis of Alzheimer's disease: report of the NINCDS-ADRDA Work Group under the auspices of Department of Health and Human Services Task Force on Alzheimer's disease. Neurology 1984;34:939-944.

12 Hughes CP, Berg L, Danziger WL, Coben LA, Martin RL: A new clinical scale for the staging of dementia. Br J Psychiatry 1982;140:566-572.

13 Folstein MF, Folstein SE, McHugh PR: 'Mini-mental state'. A practical method for grading the cognitive state of patients for the clinician. J Psychiatr Res 1975;2:189-198.

14 Fazekas F, Chawluk JB, Alavi A, Hurtig HI, Zimmerman RA: MR signal abnormalities at $1.5 \mathrm{~T}$ in Alzheimer's dementia and normal aging. Am J Neuroradiol 1987;8:421-426.

15 Report of the Expert Committee on the Diagnosis and Classification of Diabetes Mellitus. Diabetes Care 1997;20:1183-1197.

16 Minoshima S, Frey KA, Koeppe RA, Foster NL, Kuhl DE: A diagnostic approach in Alzheimer's disease using three-dimensional stereotactic surface projections of fluorine-18-FDG PET. J Nucl Med 1995;36:1238-1248.

17 Talairach J, Tournoux P: Co-Planar Stereotactic Atlas of the Human Brain. New York, Thieme, 1998.

18 Mizumura S, Kumita S, Cho K, Ishihara M, Nakajo H, Toba M, Kumazaki T: Development of quantitative analysis method for stereotactic brain image: assessment of reduced accumulation in extent and severity using anatomical segmentation. Ann Nucl Med 2003;17:289-295.

19 Hanyu H, Sato T, Shimizu S, Kanetaka H, Iwamoto T, Koizumi K: The effect of education on rCBF changes in Alzheimer's disease: a longitudinal SPECT study. Eur J Nucl Med Mol Imaging 2008;35: 2182-2190.

20 Delacourte A, David JP, Sergeant N, Buee L, Wattez A, Vermersch P, Ghozali F, Fallet-Bianco C, Pasquier F, Lebert F, Petit H, Di Menza C: The biochemical pathway of neurofibrillary degeneration in aging and Alzheimer's disease. Neurology 1999;52:1158-1165.

21 Peila R, Rodriguez BL, Launer LJ: Type 2 diabetes, APOE gene, and the risk for dementia and related pathologies. The Honolulu-Asia Aging Study. Diabetes 2002;51:1256-1262.

22 Heitner J, Dickson D: Diabetics do not have increased Alzheimer-type pathology compared with agematched control subjects. Neurology 1997;49:1306-1311.

23 Arvanitakis Z, Schneider JA, Wilson RS, Li Y, Arnold SE, Wang Z, Bennett DA: Diabetes is related to cerebral infarction but not to AD pathology in older persons. Neurology 2006;67:1960-1965.

24 Alafuzoff I, Aho L, Helisalmi S, Mannermaa A, Soininen H: $\beta$-Amyloid deposition in brains of subjects with diabetes. Neuropathol Appl Neurobiol 2009;35:60-68.

25 Beeri MS, Silverman JM, Davis KL, Marin D, Grossman HZ, Schmeidler J, Purohit DP, Perl DP, Davidson M, Mohs RC, Haroutunian V: Type 2 diabetes is negatively associated with Alzheimer's disease neuropathology. J Gerontol A Biol Sci Med Sci 2005;60:471-475.

26 Launer LJ: Diabetes: vascular or neurodegenerative: an epidemiologic perspective. Stroke 2009; 40:S53-S55.

27 Sonnen JA, larson EB, Brickell K, Crane PK, Woltjer R, Montine TJ, Craft S: Different patterns of cerebral injury in dementia with or without diabetes. Arch Neurol 2009;66:315-322.

28 Bruandet B, Richard F, Bombois S, et al: Alzheimer disease with cerebrovascular disease and vascular dementia: clinical features and course compared with Alzheimer disease. J Neurol Neurosurg Psychiatry 2009;80:133-139.

29 Ott A, Stolk RP, van Harskamp F, Pols HA, Hofman A, Breteler MM: Diabetes mellitus and the risk of dementia: the Rotterdam study. Neurology 1999;53:1937-1942. 
30 Wu JH, Haan M, Liang J, Ghosh D, Gonzalez HM, Herman WH: Impact of antidiabetic medications on physical and cognitive functioning of older Mexican Americans with diabetes mellitus: a population-based cohort study. Ann Epidemiol 2003;13:369-376.

31 Beeri MS, Schmeidler J, Silverman JM, Gandy S, Wysocki M, Hannigan CM, Purohit DP, Lesser G, Grossman HT, Haroutunian V: Insulin in combination with other diabetes medication is associated with less Alzheimer neuropathology. Neurology 2008;71:750-757.

32 Risner ME, Saunders AM, Altman JF, Ormandy GC, Craft S, Foley IM, Zvartau-Hind ME, Hosford DA, Roses AD, Rosiglitazone in Alzheimer's Disease Study Group: Efficacy of rosiglitazone in a genetically defined population with mild-to-moderate Alzheimer's disease. Pharmacogenomics J 2006; 6:246-254.

33 Forette F, Seux ML, Staessen JA, Thijs L, Babarskiene MR, Babeanu S, Bossini A, Fagard R, Gil-Extremera B, Laks T, Kobalava Z, Sarti C, Tuomilehto J, Vanhanen H, Webster J, Yodfat Y, Birkenhager WH, Systolic Hypertension in Europe Investigators: The prevention of dementia with antihypertensive treatment: new evidence from the Systolic Hypertension in Europe (Syst-Eur) study. Arch Intern Med 2002;162:2046-2052.

34 Sink KM, Leng X, Williamson J, Kritchevsky SB, Yaffe K, Kuller S, Atkinson H, Robbins M, Psaty B, Goff DC Jr: Angiotensin-converting enzyme inhibitors and cognitive decline in older adults with hypertension: results from the Cardiovascular Health Study. Arch Intern Med 2009;169:1195-1202.

35 Li NC, Lee A, Whitmer RA, Kivipelto M, Lawler E, Kazis LE, Wolozin B: Use of angiotensin receptor blockers and risk of dementia in a predominantly male population: prospective cohort analysis. BMJ 2010;340:b5409.

36 Li G, Larson EB, Sonnen JA, Shofer JB, Petrie EC, Schantz A, Peskind ER, Raskind MA, Breitner JC, Montine TJ: Statin therapy is associated with reduced neuropathologic changes of Alzheimer disease. Neurology 2007;69:878-885.

37 Dougall NJ, Bruggink S, Ebmeier KP: Systematic review of the diagnostic accuracy of $99 \mathrm{mTc}-$ HMPAO-SPECT in dementia. Am J Geriatr Psychiatry 2004;12:554-570.

38 Clark CM, Sheppard L, Fillenbaum GG, Galasko D, Morris JC, Koss E, Mohs R, Heyman A: Variability in annual Mini-Mental State Examination score in patients with probable Alzheimer disease: a clinical perspective of data from the Consortium to Establish a Registry for Alzheimer's Disease. Arch Neurol 1999;56:857-862. 